\title{
Shear tests of hollow flange channel beams with stiffened web openings
}

\author{
M. Mahendran \& P. Keerthan \\ Queensland University of Technology, Australia
}

\begin{abstract}
LiteSteel beam (LSB) is a new cold-formed steel hollow flange channel section produced using a patented manufacturing process involving simultaneous coldforming and dual electric resistance welding. The LSBs are commonly used as floor joists and bearers with web openings in residential, industrial and commercial buildings. Their shear strengths are considerably reduced when web openings are included for the purpose of locating building services. Shear tests of LSBs with web openings have shown that there is up to a $60 \%$ reduction in the shear capacity due to the inclusion of web openings. Hence there is a need to improve the shear capacity of LSBs with web openings. A cost effective way to eliminate the shear capacity reduction is to attach suitable stiffeners around the web openings. Hence experimental studies were undertaken to investigate the shear behaviour and strength of LSBs with stiffened web openings. In this research, various stiffening methods using plate and LSB stiffeners attached to LSBs using both welding and screw-fastening were attempted. Our test results showed that the stiffening arrangements recommended by past research for coldformed steel channel beams are not adequate to restore the shear strengths of LSBs with web openings. Therefore new stiffener arrangements were proposed for LSBs with web openings. This paper presents the details of this experimental study and the results including the details of the optimum stiffener details for LiteSteel beams.

Keywords: LiteSteel beams, web openings, hollow flanges, shear capacity, stiffeners, experiments, cold-formed steel structures.
\end{abstract}




\section{Introduction}

During the last two decades thin-walled and cold-formed steel sections have been used extensively in residential, industrial and commercial buildings as primary load bearing members. LiteSteel Beam (LSB) is an innovative coldformed steel hollow flange channel beam produced by OneSteel Australian Tube Mills (Figure 1(a)). It is manufactured from a single strip of high strength steel through the use of a combined cold-forming and dual electric resistance welding process. The unique cross-sectional shape of LSB with two rectangular hollow flanges was chosen such that it provides higher structural performance compared to other cold-formed steel beams produced to date. The LSB has many applications but, in particular, has become a very popular choice in the flooring systems as shown in Figure 1(b) [1].

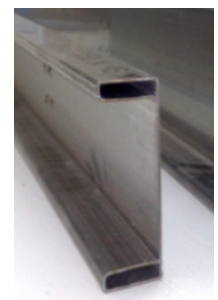

(a) LSB section

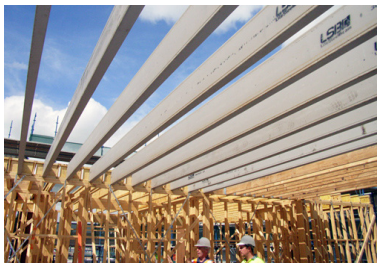

(b) LSB floor systems

Figure 1: $\quad$ LiteSteel beams [1].

Current industry application in flooring systems is to include openings in the web of floor joists or bearers so that building services such as electrical conduits and plumbing facilities can be located within them. Without web openings in beams, building services need to be located under the joists leading to increased floor heights. Pokharel and Mahendran [2] recommended the use of circular web openings in LSBs based on an investigation using finite element analyses. Three standard opening sizes of 60,102 and $127 \mathrm{~mm}$ are used with the currently available LSBs [3]. Keerthan and Mahendran [4] have shown that about $88 \%$ of the shear force is carried by the main web element of LSB. Hence the use of web openings in LSBs significantly reduces their shear capacity due to the reduced web area of LSBs. There are many variables that affect the shear capacity of members containing web openings. They include the shape, position and size of web openings and also the slenderness of the web element. Hence Keerthan and Mahendran [5] investigated the shear behaviour and strength of LSBs with circular web openings using experimental and numerical studies. New design equations were developed by them for the shear capacity of LSBs with web openings, which included the effects of enhanced buckling due to the rigid webflange juncture and post-buckling strength in shear.

Since the loss of shear capacity of LSBs was found to be as high as $60 \%$ [5] when the standard $127 \mathrm{~mm}$ web openings were used in $200 \times 45 \times 1.6 \mathrm{LSBs}$, there was a need to improve the shear capacity of LSB with web openings. There are 
several methods used to improve the shear capacity of beams with web openings. The most practical method is to increase the web thickness. However, this may not be possible with cold-formed steel sections as the thickness is governed by the manufacturing process. A cost effective way to improve the detrimental effects of a large web opening is to attach proper stiffeners around the web openings. Current cold-formed steel design standards [6, 7] and other steel framing standards [8] do not provide adequate guidelines to facilitate the design and construction of stiffeners for LSB floor joists with large web openings. Sivakumaran [9] conducted an experimental study to develop the stiffener system for cold-formed steel lipped channel beams (LCB) with web openings. However, no research has been undertaken to investigate the shear behaviour of LSBs with stiffened web openings. Therefore experimental studies were conducted to develop the optimum and economical stiffener arrangement for LSBs with web openings subjected to shear. This paper presents the details of a series of shear tests of LSBs with stiffened circular web openings, and the results. New plate stiffener arrangements have been proposed for LSBs with web openings to restore the original shear capacity of LSBs without web openings.

\section{Experimental studies}

An experimental study was conducted to evaluate the shear strength and behaviour of LSBs with stiffened web openings using a series of primarily shear tests of simply supported LSBs with stiffened web openings subjected to a midspan load (Figure 2). The results obtained from the study were used for the validation of subsequent finite element analyses, and for the purposes of developing design equations. This experimental study was aimed at developing the optimum web stiffening arrangements for LiteSteel beams with circular web openings in shear. It is vital that key parameters are chosen carefully in the design of any test program. In order to fully understand the shear performance of

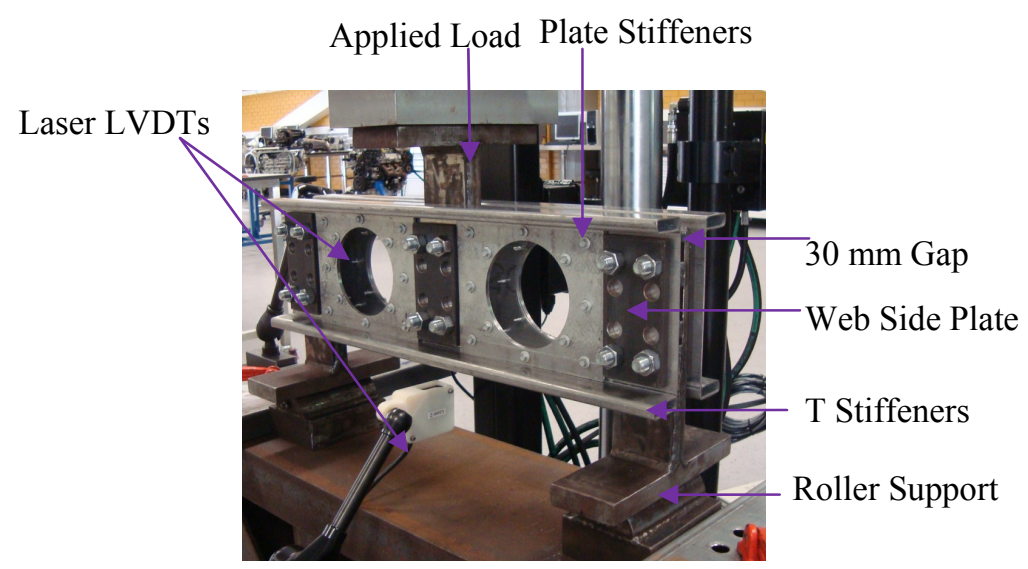

Figure 2: $\quad$ Shear test set-up of LSBs with stiffened web openings. 
LSB sections with stiffened web openings, several important issues were considered when deciding these parameters such as the ratio of the depth of web openings to clear height of web $\left(\mathrm{d}_{\mathrm{wh}} / \mathrm{d}_{1}\right)$, types and thicknesses of stiffeners, number of self-drilling Tek screws and their arrangement.

\subsection{Test specimens of LSBs}

Most commonly used LSB section, 200x45x1.6 LSB, was used in all the tests. Three opening sizes of 60,102 and $127 \mathrm{~mm}$ were chosen based on the standard sizes given in OATM [3] for 200x45x1.6 LSB sections. Plate and stud stiffeners as recommended by AISI [8] were used with varying thicknesses and sizes and screw fastening arrangements in 13 tests. Four tests were also conducted without stiffening the web openings, giving a total of 17 tests. Details of the test sepciemens are given in Table 1 . In order to simulate a primarily shear condition, relatively short test beams were selected based on an aspect ratio (shear span a/ clear web height $\mathrm{d}_{1}$ ) of 1.5 .

Table 1: $\quad$ Details of shear test specimens used in this study.

\begin{tabular}{|c|c|c|c|c|c|c|c|c|c|}
\hline $\begin{array}{c}\text { Test } \\
\text { No. }\end{array}$ & $\begin{array}{c}\text { Stiffener } \\
\text { Type }\end{array}$ & $\begin{array}{c}\mathrm{d}_{\mathrm{wh}} \\
(\mathrm{mm})\end{array}$ & $\begin{array}{c}\mathrm{t}_{\mathrm{w}} \\
(\mathrm{mm})\end{array}$ & $\begin{array}{c}\mathrm{d}_{1} \\
(\mathrm{~mm})\end{array}$ & $\begin{array}{c}\mathrm{t}_{\text {Stiff }} \\
(\mathrm{mm})\end{array}$ & $\begin{array}{c}\text { Stiffener } \\
\text { Size } \\
(\mathrm{mm})\end{array}$ & $\begin{array}{c}\text { No. of } \\
\text { Screws }\end{array}$ & $\begin{array}{c}\text { Fastening } \\
\text { Arrangement }\end{array}$ & $\begin{array}{c}\text { Shear } \\
\text { Capacity } \\
(\mathrm{kN})\end{array}$ \\
\hline 1 & - & 0 & 1.59 & 169.9 & - & - & 0 & - & 52.0 \\
\hline 2 & - & 60 & 1.61 & 169.6 & - & - & 0 & - & 41.4 \\
\hline 3 & - & 102 & 1.57 & 170.2 & - & - & 0 & - & 26.6 \\
\hline 4 & - & 127 & 1.61 & 169.6 & - & - & 0 & - & 22.2 \\
\hline 5 & PS & 102 & 1.59 & 170.1 & 1.6 & $152 \times 152$ & 20 & A1 & 33.6 \\
\hline 6 & PS & 102 & 1.57 & 170.2 & 1.6 & $152 \times 152$ & 8 & A2 & 31.9 \\
\hline 7 & PS & 102 & 1.56 & 170 & 3.2 & $152 \times 168$ & 8 & A2 & 40.1 \\
\hline 8 & PS & 102 & 1.56 & 170.5 & 4.8 & $152 \times 168$ & 8 & A2 & 44.5 \\
\hline 9 & LSB SS & 102 & 1.55 & 170.3 & 1.6 & $200 \times 168$ & 8 & A2 & 40.5 \\
\hline 10 & LSB SS & 127 & 1.55 & 169.9 & 3.2 & $200 \times 168$, & 12 & A3 & 35.6 \\
\hline 11 & PS PS & 102 & 1.56 & 170.1 & 3 & $202 \times 168$ & 12 & A3 & 54.5 \\
\hline 12 & PS & 102 & 1.57 & 170 & 3 & $202 \times 168$ & 12 & A & 52.5 \\
\hline 13 & PS & 102 & 1.57 & 168.8 & 3 & $202 \times 168$ & Welding & - & 67.0 \\
\hline 14 & PS & 127 & 1.56 & 169.9 & 5.0 & $227 \times 168$ & 12 & A3 & 47.4 \\
\hline 15 & PS & 127 & 1.57 & 170 & 5.0 & $227 \times 168$ & 12 & A5 & 46.3 \\
\hline 16 & PS & 127 & 1.57 & 170.1 & 4.8 & $177 \times 168$ & 12 & A3 & 35.6 \\
\hline PS & 60 & 1.58 & 169.8 & 1.6 & $160 \times 168$ & 12 & A3 & 50.5 \\
\hline 17 & PS & & & & & \\
\hline
\end{tabular}

Note: PS - Plate Stiffener, LSB SS - LSB Stud Stiffener, A1- Arrangement1, $t_{\text {Stiff }}, t_{w^{-}}$Thickness of Stiffener and LSB Web, $d_{w h}=$ Depth of Web Opening, $\mathrm{d}_{1}$ - Clear Height of Web. 


\subsection{Test set-up and procedure}

All LSB specimens were tested using the Tinius Olsen testing machine. Two LSB sections were bolted back to back using three T-shaped stiffeners and web side plates located at the end supports and the loading point in order to eliminate any torsional loading of test beams and possible web crippling of flanges and flange bearing failures. A $30 \mathrm{~mm}$ gap was included between the two LSB sections as shown in Figure 2 to allow the test beams to behave independently while remaining together to resist torsional effects. Figure 2 shows the experimental set-up used in the shear tests of LSBs with stiffened web openings. The support system was designed to ensure that the test beam acted as a simply supported beam with pinned supports at each end. The measuring system was set-up to record the applied load and associated test beam deflections. Two laser displacement transducers were located on the test beam under the loading point and web panel to measure the vertical and lateral deflections, respectively (see Figure 2). At the commencement of testing, a small load was applied to allow the loading and support systems to settle evenly on the bearings. The cross-head of the testing machine was moved at a constant rate of $0.7 \mathrm{~mm} /$ minute until the test beam failed in shear.

\subsection{Details of stiffening arrangements (plate and LSB stud stiffeners)}

This section presents the details of the different web stiffening arrangements attempted in this experimental study. Stiffeners were not used in Test Specimens 1 to 4 . In Test Specimen 5, the web openings were stiffened with plate stiffeners based on AISI's [8] minimum stiffening requirements. The thickness of the plate stiffener was equal to the thickness of $200 \times 45 \times 1.6$ LSB section while the plate stiffener extended $25 \mathrm{~mm}$ beyond all the edges of the web openings. This gave the dimensions $152 \times 152 \times 1.6 \mathrm{~mm}$ for the plate stiffeners of Test Specimen 5. The plate stiffener was fastened to the web of the LSB section with No.12 Tek screws at $25 \mathrm{~mm}$ spacing along the edges of the plate stiffener with an edge distance of $12.5 \mathrm{~mm}$ as shown in Figure 3 (a). This stiffener arrangement was defined as "Arrangement 1" (20 screws). Test Specimen 6 was assembled similar to Test Specimen 5. Here No.12 Tek screws were spaced at $63.5 \mathrm{~mm}$ along the edges of the plate stiffener (three screws on each side of the plate stiffener giving a total of 8 screws) with an edge distance of $12.5 \mathrm{~mm}$ (see Figure 3 (b)). This stiffener

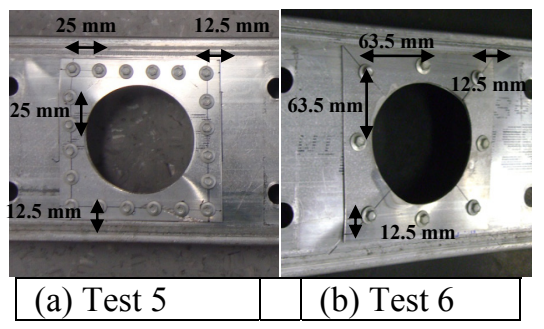

Figure 3: $\quad$ LSBs with $102 \mathrm{~mm}$ web openings and $152 \times 152 \times 1.6$ plate stiffeners. 
arrangement of using eight screws was defined as "Arrangement 2". Since the use of plate stiffeners with a thickness equal to the LSB web thickness $(1.6 \mathrm{~mm})$ did not restore the original shear capacity of LSB, two and three $1.6 \mathrm{~mm}$ plate stiffeners (total thicknesses of $3.2 \mathrm{~mm}$ and $4.8 \mathrm{~mm}$ ) were used in Test Specimens 7 and 8 , respectively. The plate stiffeners' heights were also increased to match the clear LSB web height of $168 \mathrm{~mm}$, which led to plate stiffener sizes of $152 \times 168 \times 3.2 \mathrm{~mm}$ and $152 \times 168 \times 4.8 \mathrm{~mm}$. These two specimens were fastened using eight screws (Arrangement 2) as in Test Specimen 6. It was decided to locate the screws in the middle as implied by AISI [8] recommendations. Hence, unlike in Test Specimen 6, the edge distance along the horizontal edges was 16.5 $\mathrm{mm}$ instead of $12.5 \mathrm{~mm}$ while its spacing along the vertical edges was $67.5 \mathrm{~mm}$ instead of $63.5 \mathrm{~mm}$ due to the increased height of plate stiffeners. Test 7 specimen is shown in Figure 4.

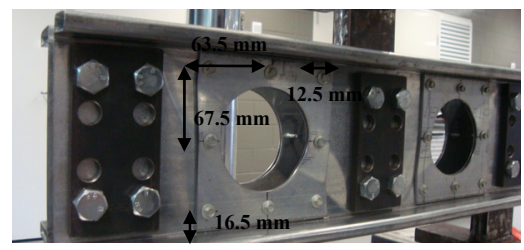

Figure 4: $\quad$ Test specimen 7 with $152 \times 168 \times 3.2 \mathrm{~mm}$ plate stiffeners.

In Test Specimen 9, 200x45x1.6 LSB stud stiffeners were attached to LSB specimen with $102 \mathrm{~mm}$ web openings while 200x45×1.6 LSB stud stiffener and $177 \times 168 \times 1.6 \mathrm{~mm}$ plate stiffener were attached to LSB specimen with $127 \mathrm{~mm}$ web openings in Test Specimen 10. In these tests, the stiffener heights were again increased to that of clear web as it was considered to improve the shear capacity. Arrangement 2 of eight screws was used in Test Specimen 9, but the edge distances and screw spacings were $16.5 \mathrm{~mm}$ and $67.5 \mathrm{~mm}$ on all four sides. The screw fastening arrangement in Test Specimen 10 was improved with four additional screws in the diagonal direction giving a total of 12 screws (Arrangement 3) as shown in Figure 5. The additional screws along the diagonal direction were located at $10 \mathrm{~mm}$ from the edge of the web openings. In order to increase the shear capacity further, $3 \mathrm{~mm}$ thick and $202 \mathrm{~mm}$ wide plate stiffeners

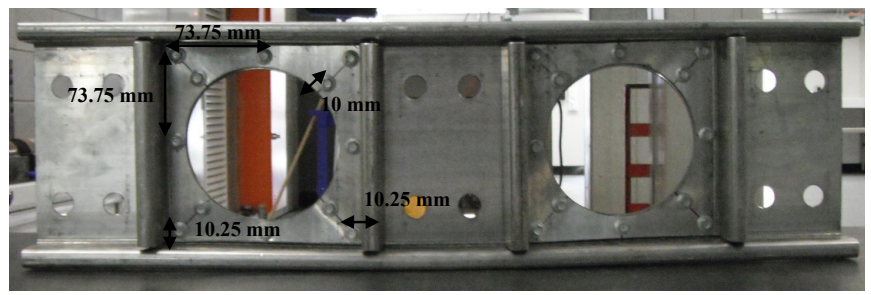

Figure 5: Test specimen 10 with $127 \mathrm{~mm}$ web openings, LSB stud stiffeners, $177 \times 168 \times 1.6 \mathrm{~mm}$ plate stiffeners and screw fastening arrangement 3. 
were used for the full web height of Test Specimens 11 and 12 (Figures 6 and 7). As in Test Specimen 10, four additional Tek screws were used to attach these $202 \times 168 \times 3.0 \mathrm{~mm}$ plate stiffeners along the diagonal direction to enhance the shear capacity of LSB with web openings. The screws were located in the middle on each side of the plate stiffener, which led to the edge distances of $25 \mathrm{~mm}$ and $16.5 \mathrm{~mm}$ and spacings of $67.5 \mathrm{~mm}$ and $76 \mathrm{~mm}$ in Test 11 (see Figure 6). However, in Test Specimen 12, the edge distances were $12.5 \mathrm{~mm}$ and $16.5 \mathrm{~mm}$ (see Figure 7). This stiffener arrangement of using 12 screws with a reduced edge distance of $12.5 \mathrm{~mm}$ was defined as "Arrangement 4". In Test Specimen $13,202 \times 168 \times 3.0 \mathrm{~mm}$ plate stiffeners were welded to LSBs with $102 \mathrm{~mm}$ web openings as shown in Figure 8 to determine whether welding instead of screwfastening would produce higher shear capacities. Test Specimen 14 was used to investigate the use of thicker $(5 \mathrm{~mm})$ and wider $(227 \mathrm{~mm})$ plate stiffeners to restore the shear capacity in the case of larger $127 \mathrm{~mm}$ web openings. Two 2.5 $\mathrm{mm}$ plates of 227x168 mm dimensions were screw fastened using 12 screws in Arrangement 3 as in Test Specimen 11. Test Specimens 15 is similar to Test Specimen 14 except in this case the plate stiffeners were attached to LSB using
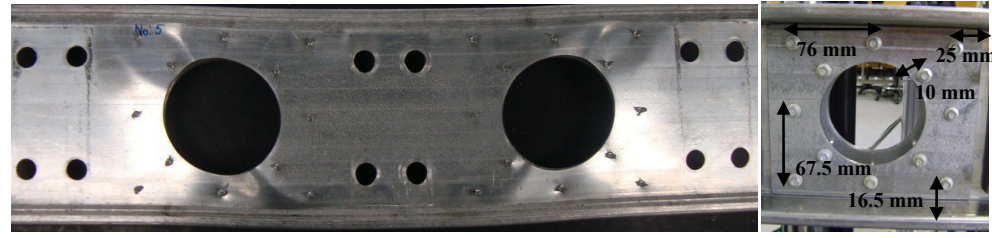

Figure 6: Test specimen 11 with screw fastening arrangement 3.

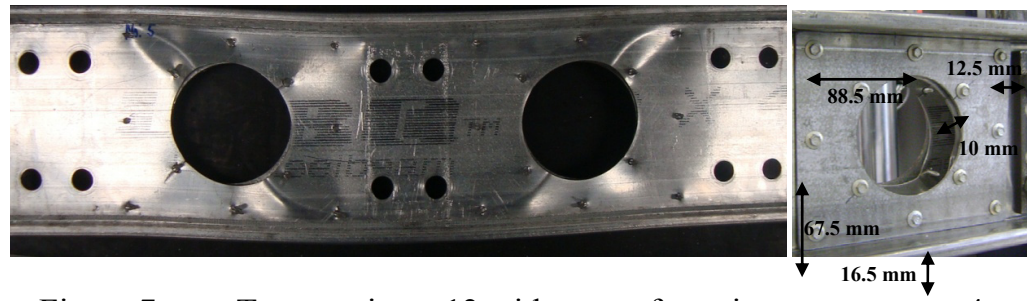

Figure 7: $\quad$ Test specimen 12 with screw fastening arrangement 4.
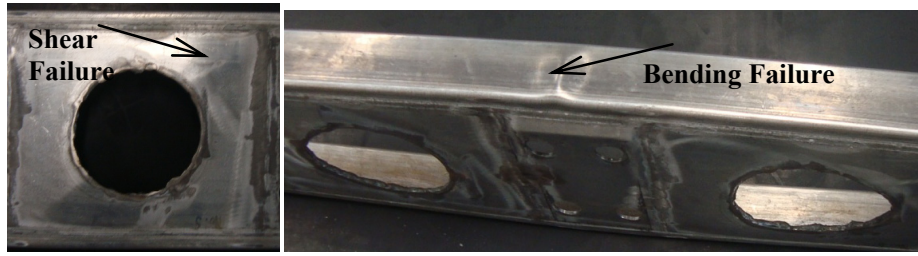

Figure 8: $\quad$ Test specimen 13 with welded plate stiffeners. 
screws located on a circular format as shown in Figure 9. This stiffener arrangement was defined as "Arrangement 5". In Test Specimen 16 the width of plate stiffeners was reduced to $177 \mathrm{~mm}$ based on AISC's (2004) recommendations while three $1.6 \mathrm{~mm}$ plate stiffeners were used giving a total thickness of $4.8 \mathrm{~mm}$. Test Specimen 17 was used with the smallest web opening of $60 \mathrm{~mm}$ for which only a single $1.6 \mathrm{~mm}$ plate stiffener was used.

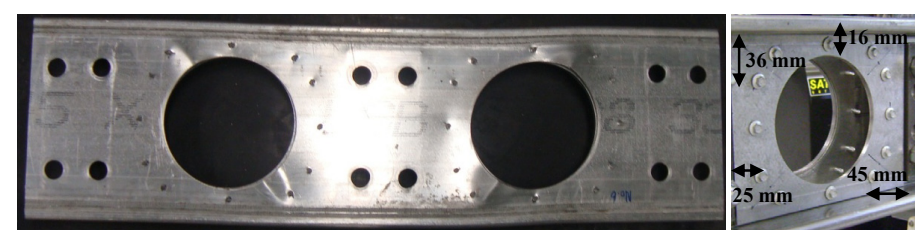

Figure 9: $\quad$ Test specimen 15 with fastening arrangement 5.

\subsection{Test results of LSBs with stiffened web openings}

The purpose of conducting full-scale shear tests is to experimentally establish the shear capacities of LSB sections with stiffened web openings. These experimental results are important as they provide a point of comparison with which to gauge the performance of the shear design rules as well as presenting some data with which to verify finite element models of LSB sections with stiffened web openings. The shear force induced in each LSB section is equal to the applied load divided by 4 in the back to back LSB test arrangement. Table 1 shows the ultimate shear capacities of the LSBs tested in this study.

In order to enhance the shear capacity of LSBs with web openings, plate stiffeners and LSB stud stiffeners were considered in this research (see Figures 3 and 5). The plate stiffeners increased the effective web thickness while also restraining the free edges of the web openings. Hence the use of plate stiffeners provided an increase in the shear capacity of LSBs as shown in Table 1. All the test specimens failed at the openings. In Test Specimen 5, plate stiffener dimensions and screw fastening arrangement were adopted based on AISI [8] (Arrangement 1). However, Test Specimen 5 only reached $65 \%$ of the shear capacity of LSB section without web openings ( $33.6 \mathrm{kN}$ vs $52 \mathrm{kN}$ ). Hence this test showed that the plate stiffeners established as per AISI [8] recommendations are not adequate to restore the shear strengths of LSB with web openings.

Tests 5 and 6 were conducted with $152 \times 152 \times 1.6 \mathrm{~mm}$ plate stiffeners attached with different screw spacing (Arrangements 1 and 2) to investigate the effect of screw spacing on the shear capacity of LSBs. Figures 3 (a) and (b) show the failure modes of LSBs in these tests while Table 1 compares their shear capacities. Figure 3 and Table 1 show that the use of screw fastening arrangement with more screws (20 versus 8 screws) only increased the shear capacity of LSBs by about $5 \%$. Tests 7 and 8 were conducted to investigate the effect of using thicker ( 3.2 and $4.8 \mathrm{~mm}$ ) plate stiffeners of full web height $(152 \times 168 \mathrm{~mm})$. These tests showed that the shear capacities increased considerably. Table 1 shows that the shear capacity of LSB with web openings 
increases with thicker and larger plate stiffeners while it did not change much due to reduced screw spacing.

In order to investigate the effect of using LSB stud stiffeners on the shear capacity of LSBs with web openings, Tests 9 and 10 were conducted. Figure 10 shows the applied load versus deflection curve for 200x45x1.6 LSB with 102 mm web openings and 200x45x1.6 LSB stud stiffeners. Figure 10 shows the presence of significant reserve capacity beyond elastic buckling. Figure 10 and Table 1 show that by using LSB stud stiffeners it was possible to achieve about $80 \%$ of the shear capacity of LSB without web openings $(52 \mathrm{kN})$ in Test 9 with $102 \mathrm{~mm}$ web openings. The use of LSB stud stiffeners provided higher shear capacities than plate stiffeners of the same thickness. However, they were not able to fully restore the shear capacity of LSBs without web openings.

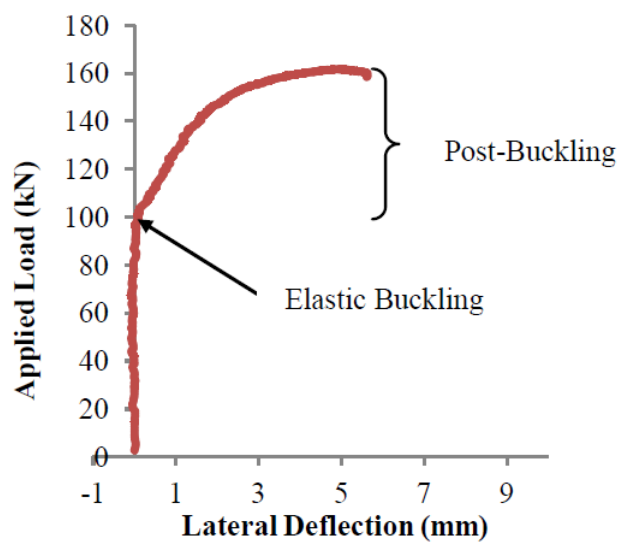

Figure 10: Applied load versus deflection for 200x45x1.6 LSB with $102 \mathrm{~mm}$ web openings and LSB stud stiffeners (Test 9).

Tests 5 to 10 showed that thicker and wider stiffeners of full web height are needed to fully restore the shear capacity of LSBs. Hence Tests 11 and 12 of LSBs with $102 \mathrm{~mm}$ web openings were conducted with $3 \mathrm{~mm}$ plate stiffeners that were $202 \mathrm{~mm}$ wide (50 mm on either side of the edge of web opening) and $168 \mathrm{~mm}$ height (full web height). They showed that these plate stiffeners could restore the full shear capacity ( 54.5 and 52.5 versus $52 \mathrm{kN})$. These tests also showed that Arrangement 4 with reduced edge distance of $12.5 \mathrm{~mm}$ led to a small reduction in the shear capacity. Hence screw fastening Arrangement 3 is recommended. Test 13 was conducted to investigate the effect of using welded plate stiffeners. Test specimen 13 failed at $67 \mathrm{kN}$ due to combined shear and bending as shown in Figure 8. This test showed that the shear capacity of LSB with web openings can be improved to levels beyond the shear capacity of a solid LSB section $(52 \mathrm{kN})$ by welding suitable plate stiffeners. However, welding is not recommended to avoid excessive heat and residual stress effects on the thin-walled cold-formed steel sections. 
As for Tests 11 and 12, Tests 14 and 15 were conducted to determine the required web thickness in the case of larger $127 \mathrm{~mm}$ web openings. They were conducted with $5 \mathrm{~mm}$ plate stiffeners that were $227 \mathrm{~mm}$ wide $(50 \mathrm{~mm}$ on either side of the edge of web opening) and $168 \mathrm{~mm}$ height (full web height). They showed that these plate stiffeners fastened using Arrangements 3 and 5 were almost able to restore the full shear capacity (91\% of the shear capacity of LSB without web openings). In this case, the depth of web opening to the clear height of web ratio $\left(\mathrm{d}_{\mathrm{wh}} / \mathrm{d}_{1}\right)$ is 0.75 , which is more than the limiting value of 0.7 given in AS/NZS 4600 [6]. Hence it is unlikely that such large openings will be used in practice. Arrangement 5 is architecturally appealing, however, it is not recommended as it can lead to additional installation costs. Test 16 was conducted with $177 \times 168 \times 4.8 \mathrm{~mm}$ plate stiffeners, and the shear capacity was only $35.6 \mathrm{kN}$ due to the use of plate stiffeners with reduced width $(177 \mathrm{~mm}$ versus $227 \mathrm{~mm}$ ). However, for Test Specimen 17 with $60 \mathrm{~mm}$ web openings, 1.6 $\mathrm{mm}$ thick plate stiffeners of 160x168 mm were able to restore the original shear capacity $(50.5$ vs $52 \mathrm{kN})$. This shows that AISI's [8] recommendation for the minimum width of plate stiffeners to be based on $25 \mathrm{~mm}$ on each side of web openings is not adequate. Test results reported in this paper show that the plate stiffeners should extend $50 \mathrm{~mm}$ beyond all the edges of the web openings.

Experimental results in Table 1 show that plate stiffeners with dimensions equal to web opening width and depth plus $100 \mathrm{~mm}$, screw fastened using Arrangement 3 are needed to restore the original shear strength of $200 \times 45 \times 1.6$ LSBs. Their thicknesses have to be a minimum of $1.6 \mathrm{~mm}, 3.0 \mathrm{~mm}$ and $5 \mathrm{~mm}$ for 200x45x1.6 LSBs with $60 \mathrm{~mm}, 102 \mathrm{~mm}$ and $127 \mathrm{~mm}$ web openings, respectively.

\section{Optimum plate stiffener arrangements for LSBs}

In this section an optimum plate stiffener system is developed for LSBs with web openings based on test results. Although tests were only conducted for $200 \times 45 \times 1.6$ LSBs, it is considered that test results reported in this paper can be used to propose a suitable stiffener system that is applicable to other LSBs. It was found that LSB stud stiffener alone was not adequate and plates also have to be used to increase the effective thickness. The use of plate stiffeners allows the designers to use appropriate widths and thicknesses. Hence plate stiffeners are proposed with the following minimum dimensions. The width of the optimum plate stiffener is $d_{w h}+100 \mathrm{~mm}$ where $d_{w h}$ is the depth of web opening while its height is lesser of clear web height $\left(\mathrm{d}_{1}\right)$ and $\mathrm{d}_{\mathrm{wh}}+100 \mathrm{~mm}$. It is recommended that these plate stiffeners are fastened to LSB webs using No.12 Tek screws and Arrangement 3. This optimum plate stiffener arrangement is an improvement of the recommendations of AISI [8] and Sivakumaran [9]. The plate stiffener does not have to extend up to the full clear web height. This is why the required plate stiffener height is lesser of $\left(\mathrm{d}_{1}\right)$ and $\mathrm{d}_{\mathrm{wh}}+100$. For example, in the case of $250 \times 75 \times 2.5 \mathrm{LSB}$ with $60 \mathrm{~mm}$ web opening the required plate stiffener sizes will be $160 \times 160 \mathrm{~mm}$ and not $160 \times 200 \mathrm{~mm}$. 
It was found that the required plate stiffener thickness depends mainly on the ratio of the depth of web opening to the clear height of web ratio $\left(\mathrm{d}_{\mathrm{wh}} / \mathrm{d}_{1}\right)$. Hence predictive equations for the thickness of optimum plate stiffeners $\left(t_{\text {stiff }}\right)$ were proposed based on $\mathrm{d}_{\mathrm{wh}} / \mathrm{d}_{1}$ (Eqns. (1) to (3)). Eqns. (1) to (3) and associated $\mathrm{d}_{\mathrm{wh}} / \mathrm{d}_{1}$ ranges were developed based on the test results reported here. Since the level of fixity at the web-flange juncture of LSB is the same for the available LSBs $(87 \%$ fixity level) [4], Eqns. (1) to (3) are considered to be applicable to all the LSB sections. Experimental results indicated that the $d_{w h} / d_{1}$ ratio has to be restricted to a value of 0.7 to restore the full shear capacity of LSB without web openings while AS/NZS 4600 also restricts this ratio to 0.7 . Hence Eqn.3 is also limited to the same value.

$$
\begin{gathered}
\mathrm{t}_{\text {Stiff }}=1.6 \mathrm{~mm}_{0.20<\frac{d_{w h}}{d_{1}} \leq 0.35} \\
\mathrm{t}_{\text {Stiff }}=3.0 \mathrm{~mm} 0.35<\frac{d_{w h}}{d_{1}} \leq 0.60 \\
\mathrm{t}_{\text {Stiff }}=5.0 \mathrm{~mm} 0.60<\frac{d_{w h}}{d_{1}} \leq 0.70 \\
\mathrm{~h}_{\text {Stiff }}= \\
\mathrm{w}_{\text {Stiff }}=\mathrm{d}_{\mathrm{wh}}+100
\end{gathered}
$$

where

$\mathrm{t}_{\text {stiff }}, \mathrm{w}_{\text {stiff, }}, \mathrm{h}_{\text {stiff }}=$ Thickness, width and height of plate stiffener

$\mathrm{d}_{\mathrm{wh}}=$ Depth of web openings

$\mathrm{d}_{1}=$ Clear height of LSB web element

Equations 1 to 3 provide a lower bound to plate stiffener thickness ( $\left.t_{\text {Stiff }}\right)$ and thus ensure a safe design of LSBs with stiffened web openings. In order to improve the accuracy of the proposed equations for the LSBs with stiffened web openings and confirm the experimental findings, a detailed parametric study based on non-linear finite element analyses will be undertaken. Keerthan and Mahendran [4] proposed suitable equations for the shear capacity of LSBs without web openings. These equations can be used for LSBs with stiffened web openings when the optimum stiffener arrangement (Arrangement 3 ) is used.

\section{Conclusions}

This paper has presented the details of an experimental investigation into the shear performance and strength of an innovative cold-formed hollow flange channel beam known as LiteSteel beams with stiffened web openings. Experimental study was conducted to develop the most suitable web stiffening arrangements for LiteSteel beams (LSB) with circular web openings in shear.

In order to investigate the effects of stiffener types (plate and stud stiffeners) and sizes (thickness, width and height) and screw fastening arrangements on the shear capacities of LSBs with web openings, 17 primarily shear tests were conducted using a three point loading arrangement. Experimental results show that the plate stiffeners based on AISI [8] recommendations are not adequate to 
restore the original shear strengths of LSBs with web openings. Suitable screwfastened stiffening systems based on plate stiffeners were developed to restore the shear capacity of LSBs with web openings. It was found that the width of the optimum plate stiffener is $d_{w h}+100 \mathrm{~mm}$ where $d_{w h}$ is the web opening depth while its height is the lesser of clear web height $\left(d_{1}\right)$ and $d_{w h}+100 \mathrm{~mm}$. The required stiffener thickness was proposed as a function of the web opening depth to clear web height ratio $\left(\mathrm{d}_{\mathrm{wh}} / \mathrm{d}_{1}\right)$. Test results also provided the required screw fastening arrangement for the optimum plate stiffeners (Arrangement 3 ).

\section{Acknowledgements}

The authors would like to thank Australian Research Council and OneSteel Australian Tube Mills for their financial support, and the QUT for providing the necessary facilities and support to conduct this research project. They would also like to thank Mr Christopher Robb and Mr Jamie Scott-Toms for their valuable assistance in performing the shear tests of stiffened LSBs. The authors would also like to thank Mr Ross Dempsey, Manager - Research and Testing, OATM, for his technical advice and support to this research project.

\section{References}

[1] LiteSteel Technologies (LST), OneSteel Australian Tube Mills, Brisbane, Queensland, viewed 10 March, 2009, <www.litesteelbeam.com.au>

[2] Pokharel, N. and Mahendran, M., Preliminary Investigation into the Structural Behaviour of LSB Floor Joists Containing Web Openings, Research Report, Queensland University of Technology, Brisbane, Australia, 2006.

[3] OneSteel Australian Tube Mills, (OATM), Design of LiteSteel Beams, Brisbane, Australia, 2008.

[4] Keerthan, P. and Mahendran, M., New Design Rules for the Shear Strength of LSBs, J. of Constructional Steel Research, Vol.67, pp. 1050-1063, 2011.

[5] Keerthan, P. and Mahendran, M., New Design Rules for the Shear Strength of LiteSteel Beams with Web Openings, Journal of Structural Engineering, ASCE, Accepted, 2011.

[6] Standards Australia/Standards New Zealand (SA), Australia/New Zealand Standard AS/NZS4600 Cold-formed Steel Structures, Sydney, Australia, 2005.

[7] American Iron and Steel Institute (AISI), North American Specification for the Design of Cold-formed Steel Structural Members, AISI, Washington, DC, USA, 2007.

[8] American Iron and Steel Institute (AISI), Supplement to the Standard for Cold-Formed Steel Framing - Prescriptive Method for One and Two Family Dwellings, 2001 Edition, AISI, Washington, DC, USA, 2004.

[9] Sivakumaran, K.S., Reinforcement Schemes for CFS Joists Having Web Openings, Research Report, Department of Civil Engineering, McMaster University, Ontario, Canada, 2008. 